\title{
Optimization of Culture Media and Conditions Enhances Mannan Oligosaccharides Production of Wickerhamomyces anomalus SZ1 Strain
}

\author{
Shobha Gupta* and Zarine P. Bhathena \\ Department of Microbiology, Bhavan's College, Andheri West, Mumbai 400058, India \\ *Corresponding author
}

\begin{tabular}{|l|}
\hline Ke y w o r d s \\
$\begin{array}{l}\text { Wickerhamomycesa } \\
\text { nomalus, Mannan } \\
\text { oligosaccharides, } \\
\text { one factor at a time } \\
\text { (OFAT) method, } \\
\text { Media optimization }\end{array}$ \\
\hline Article Info \\
\hline $\begin{array}{l}\text { Accepted: } \\
\text { 26 April } 2020 \\
\text { Available Online: } \\
\text { 10 May } 2020\end{array}$ \\
\hline
\end{tabular}

A B S T R A C T
A potential non-Saccharomyces yeast species, identified as Wickerhamomyces anomalus SZ1 strain ( Gupta, et al., 2018), which gave even higher (33\%) mannan oligosaccharides (MOS) than that obtained from the traditionally used Saccharomyces cerevisiae strain were selected for optimization of suitable media study for maximum yield of MOS by the one factor at a time (OFAT) method. Mannose was found to the best carbon source for optimum production of MOS, which significantly enhanced the yield by 1.2 folds of MOS at $2 \%$ mannose concentration as in place of dextrose in YEPD media. Higher concentration of Mannose cannot significantly $(\mathrm{p}<0.05)$ enhance the MOS production further. $2 \%$ peptone and $1 \%$ yeast extract in combination were found to be the best nitrogen source. An initial $\mathrm{pH} 6.0$, temperature $32^{\circ} \mathrm{C}$ and shaking condition at $180 \mathrm{rpm}$ for a period of 96 hours were found significantly favour the MOS production. the result revealing that $5 \%\left(1.05 \times 10^{8} \mathrm{cfu} / \mathrm{mL}\right)$ is the optimum inoculum size to attain the maximum MOS yield $(701.13 \pm 23.23 \mathrm{mg} / \mathrm{L}$ at 96 hours incubation) that was 2.0 fold higher than that to incubated at 24 hours and 1.2 fold higher to that $1 \%\left(2.1 \times 10^{7} \mathrm{cfu} / \mathrm{mL}\right)$ inoculum density but economically yield was insignificant with period of $72(656.67 \pm 23.12$ $\mathrm{mg} / \mathrm{L})$ to $96(701.13 \pm 23.23 \mathrm{mg} / \mathrm{L})$ hours incubation. It was concluded that $W$. anomalus $S Z 1$ strain can be grown on optimized media up to 72 hours and used as an alternative of $S$. cerevisiae yeast for commercial mass scale MOS production for human food and animal feed industries in future.

\section{Introduction}

Mannan oligosaccharides, a polymer of mannose sugar is a yeast derived natural sugar complex that is used as food grade growth promoters in modern livestock and poultry production and possesses marked immunological properties over the traditionally used antibiotic based growth promoters without posing any adverse effects ((Baurhoo et al., 2009; Yang et al., 2008). Most of its health-promoting properties is present within the yeast cell wall (together with glucan, chitin, and protein) with its properties varying with the fraction of polysaccharides extracted, its degree of polymerization which in most cases depends on the strain type, and its growth conditions 
(Aguilar-Uscanga and Francois, 2003; Kim and Yun, 2006; Latge, 2010). Till date, the commercial MOS production depends on Saccharomyces cerevisiae with a very little or no significant use of other species even though some have proved their commercial importance (Giovani et al., 2012; Gupta et al., 2018; Hoffman et al., 2015; Legras et al., 2007; Barnett, 2003).

This makes the present work quite significant as the demand of MOS for animal feed is increasing and it may not be possible to meet the requirement of mannan oligosaccharides (MOS) solely from Saccharomyces spps. Hence an extensive research is required to find out a non- Saccharomyces species that would be exploited as an alternative of $S$. cerevisiae for commercial MOS production. Additionally, each yeast/ fungal MOS has its own characteristic property based on the degree of polymerization that could contribute to its ability to modulate the host growth and innate immunity ((Podzorski et al., 1990; Jones and Ballou, 1969, Gupta et al., 2020). In our previous study, we conducted a performance feeding trial in Catla (Catlacatla) with extracted MOS from $W$. anomalus SZ1 (W-MOS) and MOS extracted S.cerevisiae (S-MOS) with or without probiotic (Bacillus subtilis ATCC 6633). The result exhibited that the extracted MOS from W.anomalusis at par to the commercial MOS of S.cerevisiaeto promote animal/fish production. It can be used as sole prebiotic additive or in combination with Bacillus subtilis probiotic, the growth and performance of experimental fishes effects are further enhanced without any effect on body composition [Gupta et al., 2020].

Wickerhamomyces genera has been indexed in the group of probiotic fungi due to its potentially exploitable physiological and metabolic characteristics like wide metabolic, physiological and nutritional diversity, stress tolerance; enzyme secretion, antimicrobial properties; probiotic effects and production of potential commercial metabolites (Mo et al., 2004; Gupta et al., 2018). Since till now, little attention has been paid to the ability of non- Saccharomyces yeast strains to release cell wall polysaccharides, particularly mannopolymers (Giovani et al., 2012) that exist as covalent mannose complex with protein, and can be released into extracellular medium during yeast growth and autolysis (Alexandre and Guilloux- Benatier, 2006). The present study attempts to optimize production parameters for augmenting the production of MOS with prebiotic nature from a non-Saccharomyces yeast strain Wickerhamomyces anomalus. However, the culture medium affects mannan oligosaccharides production is unknown. Therefore, the optimum conditions for the mannan oligosaccharides production were investigated for a cost effective commercial production using the one factor at a time (OFAT) process.

\section{Materials and Methods}

\section{Microorganism, media and growth conditions}

The potential yeast isolate from homemade dahi, identified as W. anomalus SZ1 (gupta et al., 2018), which gave the highest mannan oligosaccharide (MOS) yield among all isolates was selected for production study. The culture was maintained in Yeast extract peptone dextrose (YEPD) agar (HiMedia laboratories, India) slants at $4^{\circ} \mathrm{C}$ before use. One loop of potential strain on YEPD agar slant was rejuvenated separately for $24 \mathrm{~h}$ in $50 \mathrm{~mL}$ of liquid seed medium containing (per litre) $20 \mathrm{~g}$, glucose; $20 \mathrm{~g}$, peptone; and $10 \mathrm{~g}$, yeast extract at $28^{\circ} \mathrm{C}$ at $180 \mathrm{rpm}$. The cultures were centrifuged at $5000 \mathrm{rpm}$ for 10 minutes and cells were washed twice with sterilized normal saline. 
The cells were suspended in the sterilized normal saline, after which the optical density (OD) of the culture was adjusted to approximately 1.17 at $600 \mathrm{~nm}$, corresponding to a density of $2.1 \times 10^{9} \mathrm{cfu} / \mathrm{ml}$ [16].

\section{Mannan oligosaccharide extraction and purification}

Aliquot of $1 \mathrm{ml}$ of inoculum of $W$. anomalus SZ1 yeast strain at a cell density of $2.1 \times 10^{9}$ $\mathrm{cfu} / \mathrm{ml}$ (i.e. $2.1 \times 10^{7} \mathrm{cfu} / \mathrm{ml}$ in $100 \mathrm{~mL}$ ) were transferred to $250 \mathrm{ml}$ of Erlenmeyer flasks containing $100 \mathrm{ml}$ defined medium prepared by replacing one at a time carbon source and nitrogen source respectively. Additionally the influence of $\mathrm{pH}$, temperature, aeration and inoculum size on the growth of the organisms in medium was studied. Incubation of all experimental media and control were performed at RT for $96 \mathrm{~h}$ on rotary shaker at $180 \mathrm{rpm}$. While the yeast cell biomass was harvested every $24 \mathrm{~h}$ to assess its mannan oligosaccharide yield using modified Peat method (Peat et al., 1961; Nakajima and Ballou, 1974). $1 \mathrm{~g}$ cell paste (wet weight) was suspended in $5 \mathrm{~mL}$ of $0.02 \mathrm{M}$ citrate buffer ( $\mathrm{pH} 7.0)$, and the mixture was autoclaved at $125^{\circ} \mathrm{C}$ for $90 \mathrm{~min}$.

After cooling, the gelatinous solid was centrifuged and supernatant was collected. The paste was re-suspended once again in 7.5 $\mathrm{mL}$ of citrate buffer and the same procedure was followed as mentioned above. The two supernatants were combined and an equal volume of Fehling's solution was added and stirred for $2 \mathrm{~h}$. The precipitate of mannan copper complex was allowed to settle at the bottom and the major part of the liquid poured off. The copper complex of mannan was converted to mannan oligosaccharides by hydrolysis using $6 \mathrm{~mL}$ of $3 \mathrm{~N}$ hydrochloric acid. The resulting green colour solution was poured off slowly into $10 \mathrm{~mL}$ mixture of methanol and acetic acid (8:1 v/v) and the precipitate of mannan oligosaccharide was left for several hours to settle, after which it was dried and weight of precipitated mannan oligosaccharide recorded. The green colour supernatant aftermath was decanted carefully into fresh methanol-acetic acid mixture and precipitated again. This washing procedure was repeated till the supernatant was colourless. All the precipitates were then collected on a sintered glass funnel, washed thoroughly with methanol and finally with a little ethyl ether, and dried at room temperature and estimated by Dubois method (Dubois et al., 1958) and expressed mannan oligosaccharide yield in $\mathrm{mg}$ per litre.

\section{Optimization of carbon substrate for enhanced mannan oligosaccharides yield}

The experimental basal media (YEPD without carbon source) containing $1 \%$ yeast extract and $2 \%$ peptone $\mathrm{pH} 6.0$ was prepared and the carbon source was supplied by addition of $2 \%$ various sugars selected from the representative of different types of carbon groups like mannose, dextrose, fructose, mannitol, glycerol to assess its effect on the mannan oligosaccharides (MOS) production.

A control flask containing no carbon was also run during the experiment. $250 \mathrm{ml}$ of Erlenmeyer flasks containing $100 \mathrm{ml}$ of media were inoculated with $1 \mathrm{ml}(1 \%)$ of $W$. anomalus $S Z 1$ at a cell density $2.1 \times 10^{9}$ cells/ $\mathrm{ml}$ and incubated at RT on a rotary shaker. An aliquot was harvested every 24 hours over a period of 96 hours and its cell biomass analysed for its MOS yield (Vasylkovska et al., 2015).

\section{Effect of concentration of mannose}

The experimental media containing $1 \%$ yeast extract and $2 \%$ peptone $\mathrm{pH} \quad 6.0$ was supplemented with different concentration of optimized carbon source i.e. mannose ranging 
from 2 to $6 \%$ to enable the study of its effect on MOS production. The defined medium with no sugars was set up as a control.

\section{Effect of nitrogen sources}

The experimental media containing $2 \%$ mannose as optimized carbon source at $\mathrm{pH}$ 6.0 with different nitrogen sources were prepared. The nitrogen source was supplied individually as well as in combination from the representative of different types of nitrogen sources like peptone, malt extract, beef extract and yeast extract; to assess its effect on the mannan oliogosaccharide (MOS) production (Table 1). No nitrogen source was provided in the control media (Costa et al., 2002; Tremaine and Miller, 1956).

\section{Effect of PH}

The experimental media containing $2 \%$ mannose as carbon source and optimized nitrogen sources i.e. $1 \%$ yeast extract and $2 \%$ peptone was used to study the effect of $\mathrm{pH}$ variation on MOS yield. The medium $\mathrm{pH}$ was adjusted using $1 \mathrm{~N} \mathrm{NaOH}$ or $1 \mathrm{~N} \mathrm{HCl}$ to cover a range from 3.0 to 8.0 (All adjustments were made before sterilization) and then the media was autoclaved (Arroyo-López et al., 2009; Liu et al., 2015).

\section{Effect of temperature and aeration}

Optimized experimental media $(100 \mathrm{ml}$ in 250 Erlenmeyer flask) supplemented with $2 \%$ mannose, $1 \%$ yeast extract and $2 \%$ peptone at $\mathrm{pH} 6$ was used to study the effect of temperatures and aeration on mannanoligosaccharide production. For the study, two sets of the production media were prepared, one set was incubated under static condition and another set under shaker condition $(180 \mathrm{rpm})$. Each set was incubated at $\mathrm{RT}, 32^{\circ} \mathrm{C}$ and $37^{\circ} \mathrm{C}$ thereof on a rotary shaker at $180 \mathrm{rpm}$ over a period of 96 hours.

\section{Effect of inoculum size}

Optimized experimental media $(100 \mathrm{ml}$ in 250 Erlenmeyer flask) supplemented with $2 \%$ mannose, $1 \%$ yeast extract and $2 \%$ peptone at pH6.0 was used to study the effect of inoculum size on MOS production. The flasks were inoculated with inoculum range from $1 \%$ to $5 \%$ of $W$. anomalus of cell density $2.1 \times 10^{9}$ cells/ $\mathrm{ml}$. The flasks were incubated under optimized shaker condition at $180 \mathrm{rpm}$ at $32^{\circ} \mathrm{C}$ (Vasylkovska et al., 2015).

\section{Statistical analysis}

The data was statistically analysed using the statistical package SPSS version 13 in which data was subjected to two-way ANOVA and Turkey's multiple range test was used to determine the significant difference between the mean..

\section{Results and Discussion}

The commercial acceptability of prebiotic oligosaccharides from yeasts would be determined by economic factors. Environmental factors and specific culture conditions can dramatically impact cell wall oligosaccharide production in terms of yield as well as the size and chemical composition of the saccharides being formed. Thus optimization of critical parameters for the maximum production of mannan oligosaccharide like carbon and nitrogen sources, temperature and $\mathrm{pH}$ optima and inoculum sizes [25] needs to be targeted for the large scale production.

\section{Optimization of production parameters for enhanced mos yield}

\section{Carbon source}

W. anomalus SZ1 strain was grown to different carbon sources at the $2 \%$ level and 
results are given in Fig. 1. The highest MOS yield obtained with $2 \%$ mannose supplemented media was $632.33 \mathrm{mg} / \mathrm{L}$ within 96 hours, which was 2.45 fold more than that obtained within the first 24 hours and followed by dextrose supplemented media from $198.25 \mathrm{mg} / \mathrm{l}$ at 24 hours to $602.12 \mathrm{mg} / \mathrm{L}$ at 96 hours and fructose supplemented media from $215.26 \mathrm{mg} / \mathrm{l}$ at 24 hours to $524.24 \mathrm{mg} / \mathrm{L}$ at 96 hours respectively.

The MOS yield in mannitol and glycerol supplemented media showed a poor yield ranging from 45.25 to $54.25 \mathrm{mg} / \mathrm{L}$ at 24 hours and 89.75 to $124.25 \mathrm{mg} / \mathrm{L}$ at 96 hours whereas the control gave the lowest MOS yield from 25.2 (24hrs) to $51.2 \mathrm{mg} / \mathrm{L}$ (96 hrs). The two-way analysis ANOVA revealed the interaction of different carbon sources with incubation periods. A highly significant $(p<0.05)$ differences was observed in the MOS yields among the specified carbon sources whereas the MOS yield was not significantly increased from 72 to 96 hours of incubation periods. The result supported that addition of mannose in place of dextrose in YEPD media would significantly enhance 1.2 folds of MOS yield over a period of $96 \mathrm{hrs}$. The carbon studies, as expected, showed the highest yields of mannan oligosaccharides with mannose sugar containing media proving it to be a suitable substrate for enhancement of MOS production.

Our result is an agreement of AguilarUscanga and Francois (2003), they grew the yeast culture on different carbon sources like glucose, mannan, sucrose, galactose, maltose and ethanol, which were known to influence their growth behaviour. The interesting finding of their result was that the ratio of $\beta$ glucan to mannan was lower with mannose sugar supplemented media. This finding indicated that efficiency for MOS production was high with mannose in compared to other sugars.
Hence, W. anomalus SZ1 showed better growth with fermentable sugars (glucose, mannose and fructose) in comparison non fermentable sugars (mannitol and glycerol). Hence yeast cells from non-fermentable carbon sources were found to be having less growth and yield of MOS thereof.

\section{Concentration of mannose}

They are polymer of $\alpha$-D-mannose i.e. $\alpha$-DMannans, which are built of $\alpha-(1,2)-$ and $\alpha-$ $(1,3)$ - D-mannose branches which are attached to a backbone of $\alpha$-(1,6)-D-mannose chains [26]. Since mannose sugar is precursor of biosynthesis of mannan oligosaccharides, as expected, mannose as carbon source offered the highest growth rate and MOS yield among other carbon sources tested. Thus MOS yield was assessed with increasing concentration of mannose sugar and results are given in Fig. 2. The two-way ANOVA analysis revealed a statistically insignificant interaction between the concentration of mannose sugars and period of incubation in relation to MOS production. Thus supplementation of mannose sugar at $2 \%$ gave an optimal MOS yield while at higher concentration, the culture became more flocculent and hence MOS production was not further boosted.

Similarly, Aguilar-Uscanga and Francois (2003) reported that that higher concentration of mannose was not advisable for attaining growth and mannan yield. Martins et al., (2014) grew Pichia anomalus on yeast malt broth, containing dextrose $10 \%$ at $\mathrm{pH} 6.0 \pm 0.2$ and reported growth as flocculent within the media along with high amount of bioethanol and glycerol indicating that the higher concentration of carbon sources might be utilized for formation of fermentable products and not for cell wall polysaccharides biosynthesis. Similarly Li and Cai (2007) aslo reported that high concentration of sugar 
substrate supported reduced growth rate due to the formation of flocculent in the culture broth media of yeast and thus recommended less than $5 \%$ concentration of sugar substrate for cell wall polysaccharides formation.

\section{Effect of nitrogen source}

Nitrogen sources play a vital role to influence growth of microorganisms (Pavlova et al., 2004). W. anomalus SZ1 strain was grown in different nitrogen sources and results are given in Fig. 3. The highest yield of MOS obtained with treatment $\mathrm{C}$, containing $2 \%$ peptone with $1 \%$ yeast extract in media wherein MOS yield of $245.98 \pm 17.17 \mathrm{mg} / \mathrm{l}$ at 24 hours and $632.23 \pm 67.72 \mathrm{mg} / \mathrm{L}$ at 96 hours were obtained, which was 1.9 fold more than in which $3 \%$ peptone was supplemented. The lowest MOS yield as expected, was reported with no nitrogen sources i.e. $78.28 \pm 12.2$ at 24 hours and $101.12 \pm 18.23 \mathrm{mg} / \mathrm{L}$. The two-way ANOVA analysis revealed a statistically significant interaction between the specified nitrogen sources and period of incubation in relation to MOS production. The carbon nitrogen sources studies showed that along with peptone and mannose, yeast extract must be an essential media ingredient similar to YEPD for growth and optimum MOS yield obtained from of $W$. anomalus SZ1 strain.

Batista et al., (2013) used extruded bean as nitrogen source in the culture medium and recommended $1 \%$ extruded bean and $1 \%$ yeast extract or $1 \%$ yeast extract and $1 \%$ peptone present in medium gave comparable growth to the commercial YED medium for $S$. cerevisiae and $P$. pastoris GS115 strains. Martins et al., [16] used peptic digestion of animal tissues as nitrogen source in place of peptone for $P$. anomalusCE009 and reported that the growth was at par of peptone. Xiao et al., (2014) reported that organic nitrogen source gave rise to maximum production of exopolysaccharides.
They also found that supplementation of yeast extract with peptone stimulated exopolysacchrides yield (De Vuyst and Degeest, 1999). These studies revealed that peptone can be replaced with other nitrogen sources while $1 \%$ yeast extract is the most essential ingredient of yeast cells for attaining optimum growth.

\section{Effect of $\mathbf{p H}$}

The $\mathrm{pH}$ of a cell's surrounding environment affects intracellular $\mathrm{pH}$, which in turn alters the enzymatic activity within cells, leading to cell growth. $W$. anomalus SZ1 strain was grown at different $\mathrm{pH}$ ranging from 3 to 8 and result is given in Fig. 4. The highest MOS yield obtained with the media having $\mathrm{pH} 6.0$ was $257.65 \pm 8.9 \mathrm{mg} / \mathrm{l}$ at 24 hours and $635.56 \pm 23.23 \mathrm{mg} / \mathrm{L}$ at 96 hours, followed by $215.26 \pm 9.8$ at 24 hours to $423.9 \pm 23.23 \mathrm{mg} / \mathrm{L}$ at 96 hours with media having $\mathrm{pH} 5.0$ and $87.65 \pm 5.15$ at 24 hours to $356.23 \pm 21.21 \mathrm{mg} / \mathrm{L}$ at 96 hours with media having $\mathrm{pH}$ 4.0. The lowest MOS yield was reported with media having $\mathrm{pH} 3.0$ i.e. $25.2 \pm 2.21 \mathrm{mg} / \mathrm{l}$ at 24 hours and $48.2 \pm 2.67 \mathrm{mg} / \mathrm{L}$ at 96 hours.

When the $\mathrm{pH}$ of media increased from 6 to 8 , yield decreased significantly from $124.25 \pm 3.65$ to $89.75 \pm 6.21 \mathrm{mg} / \mathrm{L}$ over a period of 96 hours. The two-way analysis thus revealed that the interaction of different $\mathrm{pH}$ with incubation periods shows a significant $(p<0.05)$ differences in the MOS yields, with $\mathrm{pH}$ of mannose supplemented defined media of 6.0 best supporting the growth and optimum MOS yield from $W$. anomalus SZ1 strain.

Wang and $\mathrm{Lu}$ (2004) observed that the initial medium $\mathrm{pH}$ is a critical factor associated with the growth and exopolysaccharides biosynthesis. They studied the effect of different $\mathrm{pH}$ on exomannan production by marine yeasts and found the optimum initial 
$\mathrm{pH}$ of the basal medium should not less than 5.6. The results also showed that when the initial $\mathrm{pH}$ was lower than 5.6, MOS production decreased, indicating that yeast strain was very sensitive to initial $\mathrm{pH}$ (Heald and Kristiansen, 1985; Adami and Cavazzoni, 1990; Elinv, 1992). Similarly Tao et al., (2011) studied the effects of $\mathrm{pH}$ on the $P$. anomalus growth and reported that the growth decreased $\mathrm{pH}$ ranged from 3.0 to 4.5 while the medium $\mathrm{pH}$ fluctuation between 5.0 to $6.0 \mathrm{did}$ not affect the growth rate though within the range from 6.5 to 7.5 , it underwent a remarkable decreased in growth. Thus they recommended the initial optimum $\mathrm{pH}$ for $P$. anomalus is 5.0 and found a tolerance limit from 4.5 to 6.0 .

\section{Effect of temperature and aeration}

The effect of temperature and aeration on MOS yields was presented in Fig. 5. The results clearly reflected a significant $(p<0.05)$ difference that showed the effect of temperature and aeration on growth and MOS yield. The highest yield of MOS obtained from the $W$. anomalus SZ1 strain cultured at $32^{\circ} \mathrm{C}$ within shaker flask conditions at 180 $\mathrm{rpm}$ was $257.65 \pm 9.78 \mathrm{mg} / \mathrm{l}$ at 24 hours and $654.12 \pm 19.76 \mathrm{mg} / \mathrm{L}$ at 96 hours, which was 1.2 fold more than that obtained without shaking of flasks. The lowest MOS yield was reported with room temperature without shaking the flask i.e. $167.66 \pm 7.56$ at 24 hours and $423.9 \pm 17.12 \mathrm{mg} / \mathrm{L}$.

There exists a highly significant $(\mathrm{p}<0.05)$ differences in the average MOS yields among the different temperature and aeration condition with incubation periods. The rest of the temperature like RT and $37^{\circ} \mathrm{C}$ with or with the shaking of flask poorly supported the growth of $W$. anomalus SZ1 strain hence yield was reported in the range of 167.66 to $201.12 \mathrm{mg} / \mathrm{l}$ at 24 hours and 345.24 and $412.23 \mathrm{mg} / \mathrm{L}$ at 96 hours respectively.
The two-way ANOVA interaction between temperature and aeration along with incubation showed a significant $(p<0.05)$ difference. The result revealed that the optimum temperature was $32^{\circ} \mathrm{C}$ with aeration for optimum MOS yield.

The temperature and aeration are important in growth of microorganisms and enhancing their productivity for commercially important products like alcohol, organic acids, alkaloid, flavonoid, polysaccharides and its oligosaccharides, single cell proteins, essential amino acids, vitamins and secondary metabolites was used for human and animal food and feed industries. Tao et al., (2011)reported that $P$. anomalus viable cell counts increased as temperature was increased from 25 to $30^{\circ} \mathrm{C}$ after which it declined sharply when the temperature increased from 35 to $45^{\circ} \mathrm{C}$, indicating that $32^{\circ} \mathrm{C}$ was the optimum temperature and $40^{\circ} \mathrm{C}$ and above temperature might be lethal for $P$. anomalus. Martins et al., (2014) reported that the optimum growth of $P$. anomalus CE009 was reached at the temperature ranging from 25 to $30^{\circ}$ C. Similarly, Hanneh et al., (2014) found that mannan content increased linearly, attaining the maximum yield $(95.447 \pm 8.8$ $\mathrm{mg} / 100 \mathrm{ml}$ ) at $32^{\circ} \mathrm{C}$ under aeration. Similarly Liu et al., (2009) studied the effect of temperature on mannan production and reported a maximum yield $(71.25 \mathrm{mg} / 100 \mathrm{ml})$ at $32^{\circ} \mathrm{C}$ and thereafter a significant decrease in exomannan production was seen at higher temperature. This was nearly similar to our findings and supported by several previously reports, concerning the optimum temperature and aeration of exopolysaccharides (Cho et al., 2001; Heald and Kristiansen, 1985; Adami and Cavazzoni, 1990; Elinov et al., 1992).

\section{Effect of inoculum size}

The initial inoculum density added to broth for MOS production showed a highly 
significant $(\mathrm{p}<0.05)$ differences on the yield wherein the yield was found to increase with the increase in the period of incubation in all treatments (Fig. 6). The highest MOS yield was reported from $378.15 \pm 17.13$ at 24 hours to $701.13 \pm 23.23 \mathrm{mg} / \mathrm{L}$ at 96 hours incubation with inoculum density of $5 \%\left(1.05 \times 10^{8}\right.$ $\mathrm{cfu} / \mathrm{mL})$, followed by $312.15 \pm 14.15$ to $688.35 \pm 22.23$ with $4 \%\left(8.4 \times 10^{7} \mathrm{cfu} / \mathrm{mL}\right)$, $276.45 \pm 13.13$ to $665.78 \pm 21.78$ with $3 \%$ $\left(6.3 \times 10^{7} \quad \mathrm{cfu} / \mathrm{mL}\right), \quad 212.12 \pm 13.13$ to $645.90 \pm 21.21$ with $2 \%\left(4.2 \times 10^{7} \mathrm{cfu} / \mathrm{mL}\right)$ and $198.25 \pm 12.14$ to $623.12 \pm 19.78 \mathrm{mg} / \mathrm{L}$ at 96 hours with $1 \%\left(2.1 \times 10^{7} \mathrm{cfu} / \mathrm{mL}\right)$ incubation respectively. The two-way ANOVA interaction between inoculum density and MOS yields showed a highly significant $(p<0.05)$ differences with the result revealing that $5 \%\left(1.05 \times 10^{8} \mathrm{cfu} / \mathrm{mL}\right)$ is the optimum inoculum size to attain the maximum MOS yield of 1.2 fold higher to that $1 \%\left(2.1 \times 10^{7}\right.$ $\mathrm{cfu} / \mathrm{mL}$ ) inoculum density whereas there was not a significant increase in the MOS production from 72 to 96 hours. The incubation up to 72 hours with in optimized condition will be more economically practical for mass scale production of MOS by $W$. anomalus SZ1 strain.

Table.1 Different nitrogen sources added to modified YEPD media

\begin{tabular}{|l|l|}
\hline Flask & Nitrogen source \\
\hline A & $2 \%$ peptone \\
\hline B & $3 \%$ Peptone \\
\hline C & $2 \%$ peptone $+1 \%$ yeast extract \\
\hline D & $2 \%$ peptone $+1 \%$ Beef extract \\
\hline E & $2 \%$ peptone $+1 \%$ Malt extract \\
\hline F & No nitrogen source \\
\hline
\end{tabular}

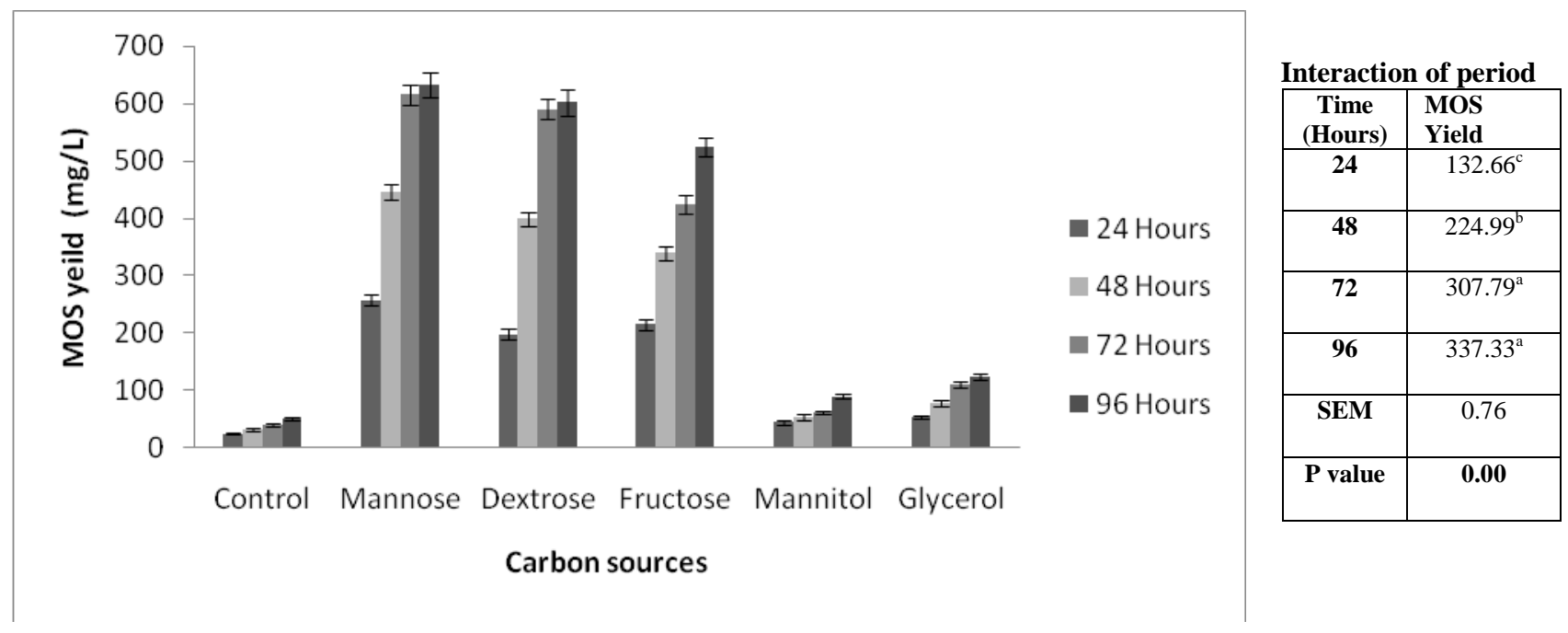

Interaction of carbon sources

\begin{tabular}{|c|c|c|c|c|c|c|c|}
\hline Control & Mannose & Dextrose & Fructose & Mannitol & Glycerol & SEM & P Value \\
\hline $37.67^{\mathrm{E}}$ & $488.05^{\mathrm{A}}$ & $447.84^{\mathrm{B}}$ & $375.65^{\mathrm{C}}$ & $62.96^{\mathrm{D}}$ & $91.98^{\mathrm{D}}$ & 9.40 & 0.00 \\
\hline
\end{tabular}

Data is presented as Mean $\pm \mathrm{SE}(\mathrm{n}=3)$ values with different superscripts in the same column differ significantly $(\mathrm{p}<0.05)$ 
Fig.1 Effect of different carbon sources on mannan oligosaccharides yield

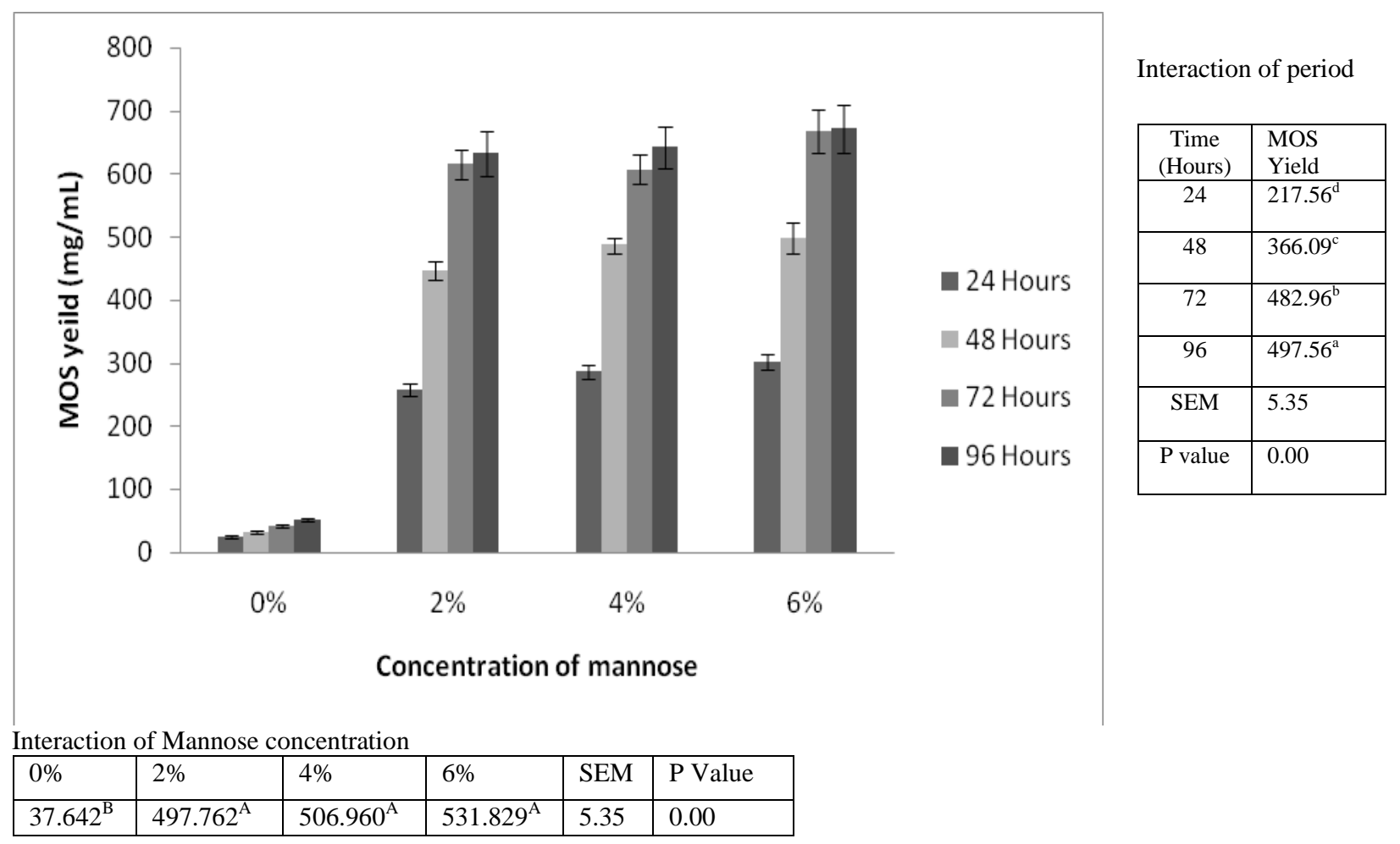

Data is presented as Mean $\pm \mathrm{SE}(\mathrm{n}=3)$ values with different superscripts in the same column differ significantly $(\mathrm{p}<$ $0.05)$

Fig.2 Effect of mannose concentration on Mannan oligosaccharides Yield

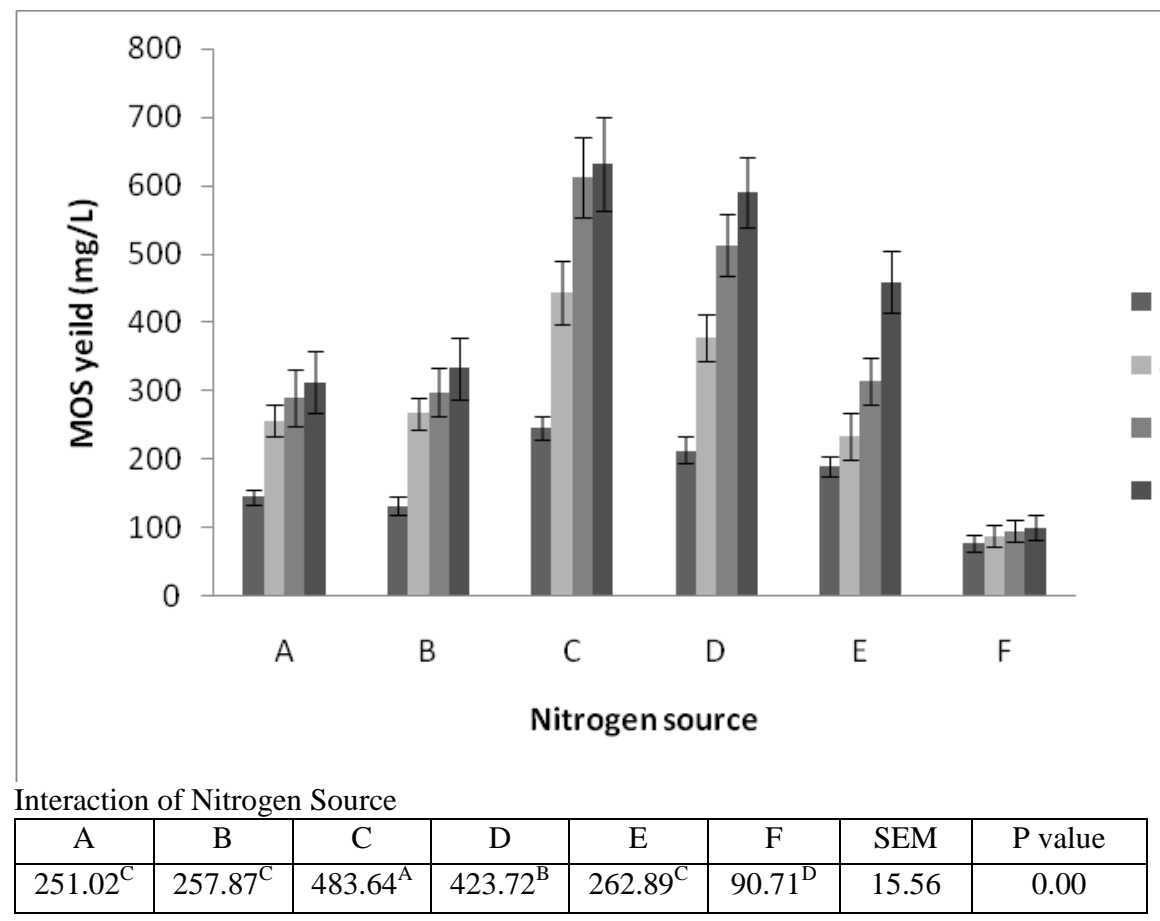

Data is presented as Mean \pm SE $(n=3)$ values with different superscripts in the same column differ significantly $(\mathrm{p}<$ $0.05)$ 
Fig.3 Effect of nitrogen source on mannan oligosaccharides yield

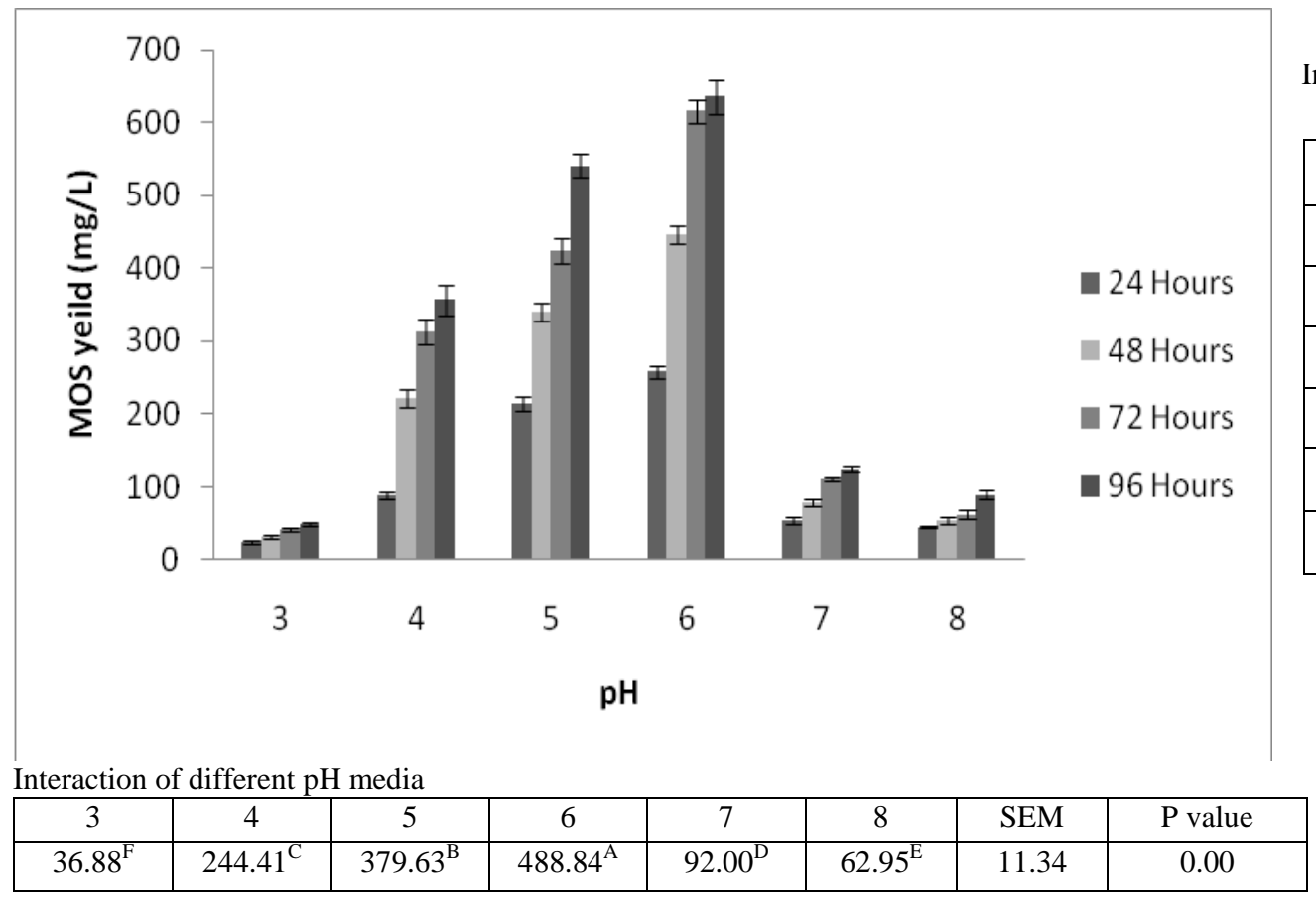

Interaction of period

\begin{tabular}{|c|c|}
\hline $\begin{array}{c}\text { Time } \\
\text { (Hours) }\end{array}$ & $\begin{array}{l}\text { MOS } \\
\text { Yield }\end{array}$ \\
\hline 24 & $114.21^{\mathrm{c}}$ \\
\hline 48 & $195.33^{\mathrm{b}}$ \\
\hline 72 & $261.25^{\mathrm{a}}$ \\
\hline 96 & $299.01^{\mathrm{a}}$ \\
\hline SEM & 9.76 \\
\hline P value & 0.00 \\
\hline
\end{tabular}

Data is presented as Mean $\pm \mathrm{SE}(\mathrm{n}=3)$ values with different superscripts in the same column differ significantly $(\mathrm{p}<0.05)$

Fig.4 Effects of pH on mannan oligosaccharides yield

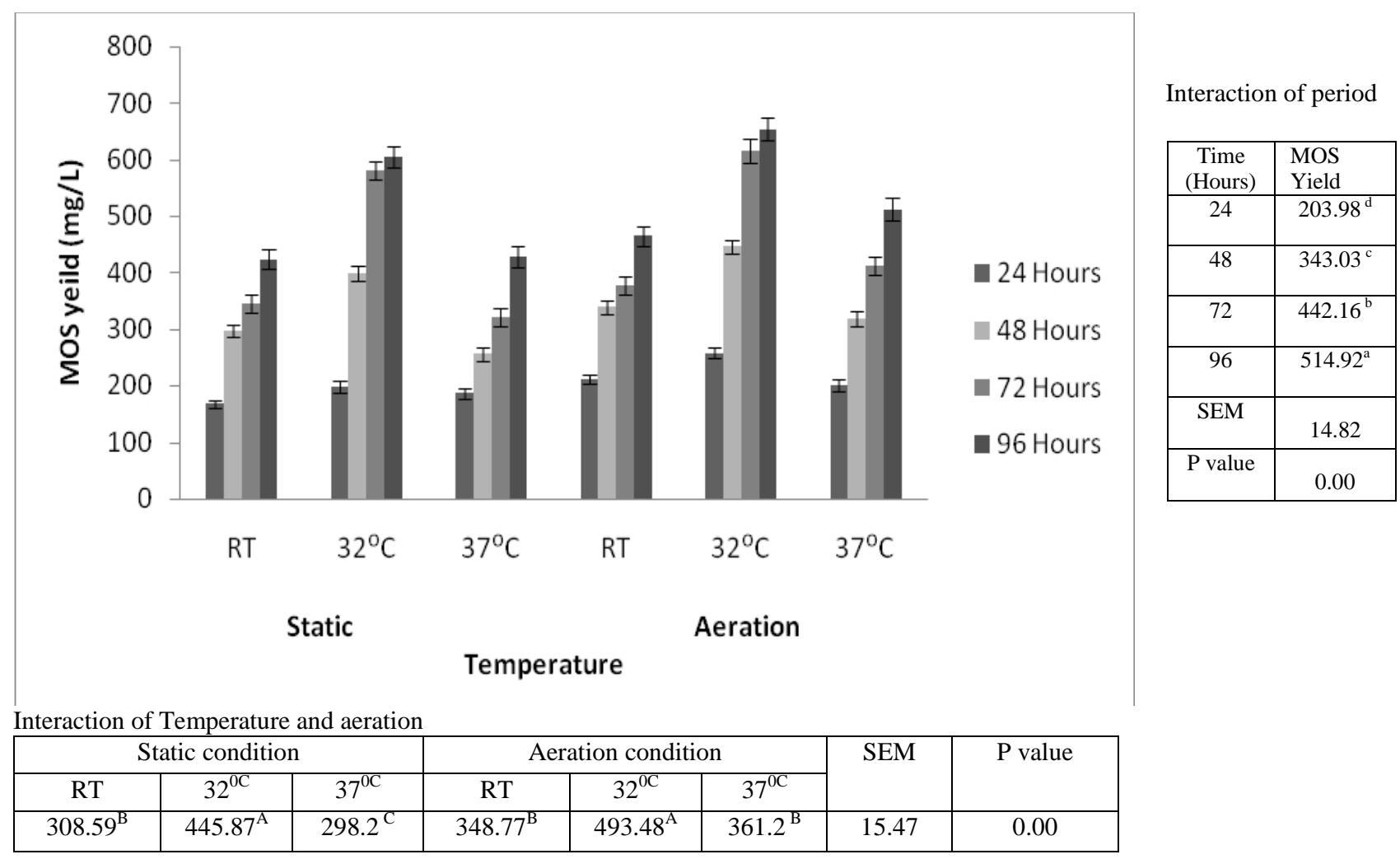

Data is presented as Mean $\pm \operatorname{SE}(n=3)$ values with different superscripts in the same column differ significantly $(\mathrm{p}<0.05)$ 
Fig.5 Effect of temperature and aeration on mannan oligosaccharides yield

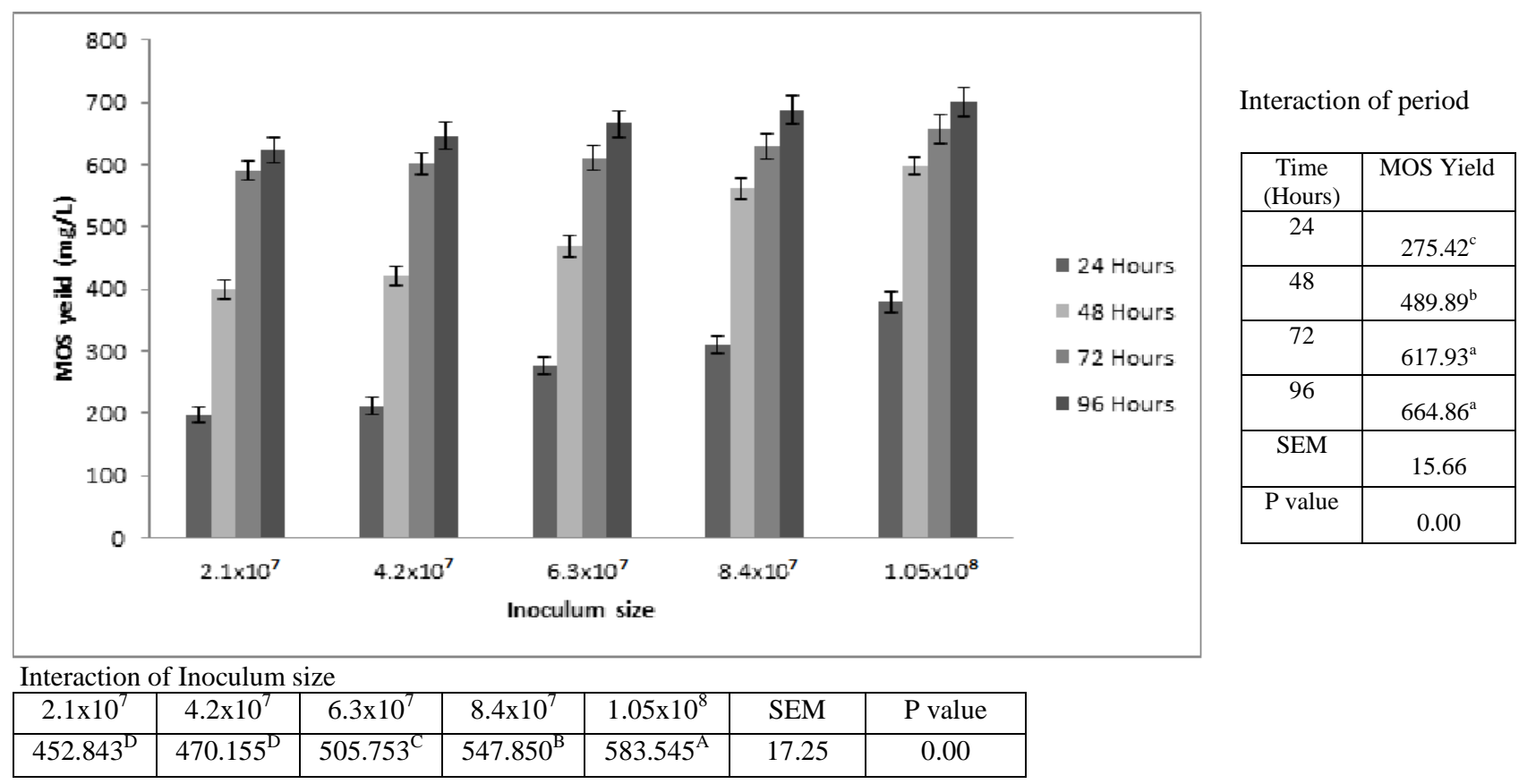

Data is presented as Mean $\pm \operatorname{SE}(n=3)$ values with different superscripts in the same column differ significantly $(\mathrm{p}<0.05)$

Fig.6 Effects of inoculum size on mannan oligosaccharides Yield

Tao et al., (2011) observed the effect of inoculum size of $P$. anomalus on the fermentation process. The biomass increased steadily, when the inoculum varied from 3 to $5 \%$. There was a moderate decrease, when inoculum varied from 5 to $6 \%$. In contrast a notable decrease was observed between inoculum of 6 to 7\%. Tao et al., (2011) findings supported that $5 \%$ inoculum size was the optimum for attaining maximum growth and mannan oligosaccharides yield thereof. Consequently, a sound understanding of growth parameters is essential to achieve optimum production of mannan oligosaccharides. The present study demonstrated that the optimum culture condition for Wickerhamomyces anomalus SZ1 was a temperature of $32^{\circ} \mathrm{C}, \mathrm{pH} 6.0$ and inoculum size of $5 \%$ in defined media containing $2 \%$ mannose sugar, $1 \%$ yeast extract and $2 \%$ peptone gave maximum yield of $701.13 \pm 23.23 \mathrm{mg} / \mathrm{L}$ mannan oligosaccharides. The Two-Way ANOVA analysis revealed that there was no significant economical yield benefit of MOS from 72 to 96 hours under optimization condition. Under these optimum conditions, W. anomalusSZ1 straincan be exploited as an alternative of Saccharomyces cerevisiae yeast strain for the mass production of MOS as dietary prebiotic supplement for promoting better growth and innate immune performances of terrestrial animals and fishes.

\section{Acknowledgments}

The author (S.G.) is thankful to Dr. K. N. Ghorude, Principal, Vartak College, Vasai West, DistPhalghar, India for granting kind permission to pursue degree under in-service Ph.D. Program of Mumbai University, Mumbai, India.

\section{References}

Adami, A. and Cavazzoni, V. 1990 Exopolysaccharides produced by some 
yeast strains. Annali di Microbiologiaed Enzimologia. 40: 245-253.

Aguilar-Uscanga, B.and Francois, J. M. 2003. A study of the yeast cell wall composition and structure in response to growth conditions and mode of cultivation. Letters in Applied Microbiology. 37: 268-274.

Alexandre, H. and Guilloux-Benatier, M., 2006. Yeast autolysis in sparkling wine -a review. Australian Journal of Grape and Wine Research. 12: 119-127.

Arroyo-López, F. N., Orlić, S., Querol, A and Barrio, E. 2009. Effects of temperature, $\mathrm{pH}$ and sugar concentration on the growth parameters of Saccharomyces cerevisiae, S. kudriavzevii and their interspecific hybrid. International Journal of Food Microbiology. 131:120-127.

Barnett, J. A. 2003. Beginnings of microbiology and biochemistry: the contribution of yeast research. Microbiol (Reading, Engl.). 149 (3): 557-567.

Batista, K. A. Artur, L., BatausbIvan, M., Campos, T. N. and Fernandes, K. F. 2013. Development of culture medium using extruded bean as a nitrogen source for yeast growth. Journal of Microbiological Methods. 92 (3): 310315.

Baurhoo, B., P. R. Ferket, and X. Zhao (2009) Effects of diets containing different concentrations of mannanoligosaccharide or antibiotics on growth performance, intestinal development, cecal and litter microbial populations, and carcass parameters of broilers. Poult. Sci. 88: 2262-2272.

Costa, E., Usall, J., Teixido, N., Garcia, N., and Vinas, I. 2002.Effect of package and storage conditions on viability and efficacy of the freeze-dried biocontrol agent Pantoeaagglomérons strain CPA2.J. Appl. Microbiol. 92:873-878.
De Vuyst, L., Vanderveken, F., van-den Ven, S and Degeest, B. 1998. Production by and isolation of exopolysaccharides from Streptococcus thermophilus grown in a milk medium and evidence for their growth associated biosynthesis. J. Appl. Microbiol. 84:1059-1068.

Dubois, M., Gilles, K.A., Hamilton, J.K., Rebers, P.A. and Smith, F. 1956.Colorimetric method for determination of sugars and related substances. Anal. Chem. 28: 350-356.

Elinov, N. P., Ananyeva, E. P., Vitovskaya, G.A. 1992. Peculiarities of biosynthesis and characteristics of exoglucanes in yeasts of Sporobolomyces genus. Microbiologiya. 4: 615- 621.

Giovani, G., Rosi, I. and Bertuccioli, I. 2012. Quantification and characterization of cell wall polysaccharides released by non- Saccharomyces yeast strains during alcohol fermentation. Int J Food Microbiol, 160: 113-118.

Gupta S., Z. A. Bhathena, S. Kumar, P. P. Srivastava, and S. B. Jadhao (2018) Quantification and characterization of mannan oligosaccharide producing yeasts isolated from various food products. ProcNatlAcad Sci. India Sect. B BiolSci 88(3):1237-1247. https://doi.org/10.1007/s40011-0170859-7

Gupta, S., Z. P. Bhathena, S. Kumar, P. P. Srivastava, S. Gupta, and S. B. Jadhav (2020) Comparative efficacy of mannan-oligosaccharides from two yeast species fed alone or in combination with probiotic Bacillus subtilis ATCC 6633 to Catla (Catla catla) juveniles. Aquaculture International. 28: 691-710.

Hanneh, V. A., Ali, M. S., Elnaz, M., Arash, K. and Masoome, M. 2014. Statistical Optimization of Culture Media and Conditions for Maximize Production of 
Mannan by Saccharomyces Cerevisiae Using Response Surface Methodology. Annual Research \& Review in Biology.4(12): 1927-1940

Heald P.J. and Kristiansen, B. 1985 Synthesis of polysaccharide by yeast-like forms of Aureobasidium pullulans. Biotechnology and Bioengineering. 27: 1516-1519.

Hoffman, C. S., Wood, V. and Fantes, P. A. 2015. An Ancient Yeast for Young Geneticists: A Primer on the Schizosaccharomyces pombe. Model Sys Gen. 201:403-423.

Jones, G.H. and Ballou, C.E. 1969. Studies on the Structure of Yeast Mannan. The J BiolChem, 244: 1043-1051.

Kim, K. S. and Yun, H. S. 2006.Production of soluble $\beta$-glucan and manan from the cell wall of Saccharomyces cerevisiae.Enzyme and Microbial Technology. 39: 496-500.

Kim, K. S. and Yun, H. S. 2006.Production of soluble $\beta$-glucan and manan from the cell wall of Saccharomyces cerevisiae. Enzyme and Microbial Technology. 39: 496-500.

Latgé, J. P. 2010. Tasting the fungal cell wall. Cell Microbiol. 12(7):863-872.

Legras, J. L., Merdinoglu, D., Cornuet, J. M. and Karst, F. 2007. Bread, beer and wine: Saccharomyces cerevisiae diversity reflects human history. Mol Ecol. 16(10): 2091-2102.

Li, J. R. and Cai, A. Q. 2007. Isolation and identification of main microorganisms in traditional distiller's yeast. LiquorMaking Sci. Tech, 5: 111-115.

Liu, H., Wang, Q., Liu, Y. Y. and Fang, F. 2009. Statistical optimization of culture media and conditions for production of mannan by Saccharomyces cerevisiae. Biotechnology and Bioprocess Engineering.14: 577-583.

Liu, X., Jia, B., Sun, X., Ai, J., Wang, L., Wang, C., Zhao, F., Zhan, J. and Huang,
W. 2015. Effect of initial $\mathrm{pH}$ on growth characteristics and fermentation properties of Saccharomyces cerevisiae. J Food Sci. 80(4): M800-808.

Martins, S. C. S., Aragão, V. O. and Martins, C. M. 2014.Pichia spp. yeasts from Brazilian industrial wastewaters: Physiological characterization and potential for petroleum hydrocarbon utilization and biosurfactant production. African Journal of Microbiology Research. 8(7): 664-672.

Mo, E.K., Lee, J.H., Xu, B.J. and Sung, C.K. 2004. Identification of yeasts from Korean faeces and prerequisite characterisation for preparation of probiotics. Food SciBiotechnol. 13:6370.

Nakajima, T. and Ballou, C. E. 1974. Characterization of the carbohydrate fragments obtained from Saccharomyces cerevisiae mannan by alkaline degradation. J. Biol. Chem. 249: 7679-7684.

Pavlova, K, Panchev, I. and Hristozova, T. $2005 . \quad$ Physico-chemical characterization of exomannan from Rhodotorula acheniorum MC. World Journal of Microbiology \& Biotechnology. 21: 279-282.

Peat, S, Whelan, W. J. and Edwards, T. E. 1961.Polysaccharides of baker's yeast. Part IV.Mannan.J Chem. Soc 1: 29-34.

Podzorski, R. P., Gray, G. R. and Nelson, R. D. 1990. Different effects of native Candida albicans mannan and mannanderived oligosaccharides on antigenstimulated lymphoproliferation in vitro. Journal of Immunology (Baltimore). 144: 707-716.

Rayner J. C., and S. Munro S (1998) Identification of the MNN2 and MNN5 mannosyltransferases required for forming and extending the mannose branches of the outer chain mannans of Saccharomyces cerevisiae. J Biol Chem. 
273:26836-26843.

Tao, N., Gao, Y. and Liu, Y. 2011. Isolation and characterization of a Pichiaanomala strain: a promising candidate for bioethanol production. Braz. J. Microbiol. 42: 668-675.

Tremaine, J. H. and Miller, J. J. 1956. Effect of yeast extract, peptone, and certain nitrooen compounds on sporulation of Saccharomyces cerevisiae. Mycopathologiae tmycologia applicate. 7: 241-250.

Vasylkovska, R. Petriv, N. and Semchyshyn, H. 2015. Carbon Sources for Yeast Growth as a Precondition of Hydrogen Peroxide Induced Hormetic Phenotype. International Journal of Microbiology. http://dx.doi.org/10.1155/2015/697813.

Wang, Y. X. and Lv, Z. X. 2004.Statistical optimization of media for extracellular polysaccharide by Pholiotasquarrosa (Pers. ex Fr.) Quel. AS 5.245 under submerged cultivation. Biochemical Engineering Journal. 20: 39-47.

Xiao, J.H., Chen, D.X., Xiao, Y., Liu, J.W., Liu, Z.L., Wan, W.H., Fang, N. and Tan, B.B. 2004. Optimization of submerged culture conditions for mycelial polysaccharide production in Cordycepspruinosa. Process Biochem. 39: 2241-2247.

Yang, Y., P.AIji, A. Kocher, L. L. Mikkelsen, and M. Choct (2008) Effects of mannanoligosaccharide and fructooligosaccharide on the response of broilers to pathogenic Escherichia coli challenge. British Poultry Science. 49 (5): 550-559.

\section{How to cite this article:}

Shobha Gupta and Zarine P. Bhathena. 2020. Optimization of Culture Media and Conditions Enhances Mannan Oligosaccharides Production of Wickerhamomyces anomalus SZ1 Strain. Int.J.Curr.Microbiol.App.Sci. 9(05): 3104-3117. doi: https://doi.org/10.20546/ijcmas.2020.905.368 